\title{
Content Analysis of Whatsapp Conversations: An Analytical Study to Evaluate the Effectiveness of Whatsapp Application in Karachi
}

\author{
Sana Shahid* \\ The researcher is currently enrolled in PhD program at University of Karachi and teaching as an Adjunct \\ faculty member at a leading private media institute of Karachi, Pakistan
}

\begin{abstract}
*Corresponding Author: Sana Shahid, The researcher is currently enrolled in PhD program at University of Karachi and teaching as an Adjunct faculty member at a leading private media institute of Karachi, Pakistan
\end{abstract}

\begin{abstract}
WhatsApp application has recently emerged as a substitute of SMS in developing countries. It includes a variety of functions such as sharing live location, files, video, audio and text messages to any part of the world. The increasing trend of WhatsApp messenger as an innovative communication application in the metropolitan city Karachi is a matter of newer subject of interest that needs evaluation and research based understanding. It generates huge volume of data which has not yet been researched thoroughly in Pakistan. Therefore, the present study was conducted with an aim to analyze the WhatsApp of WhatsApp conversations. It also aimed at exploring the frequency and composition of WhatsApp users along with usage and nature of their conversations. The research methodology includes quantitative and qualitative data. In this regard, a total of 50 private and group conversations of 15 days were collected from 25 students and 25 professionals. The quantitative data was analyzed through python programming language. It was discovered that a total number of 66,327 messages, 869,404 words and 6163 media files were sent by 2,023 WhatsApp users in 30 days. It was also discovered that students are using WhatsApp more than Professionals. Furthermore, standard word formation process was also observed. It was also discovered that both students and professionals use WhatsApp to achieve their academic and business goals. They use WhatsApp to build their interpersonal relationships. It's also a source of entertainment for them. It is concluded that it is indispensible to revolutionize and adopt the latest technology in order to dilute the emerging challenges in Pakistan.
\end{abstract}

Keywords: Smart Phone; Pakistani Whatsapp Users; Whatsapp Conversation; Whatsapp Analysis, Business, Language, Studies, Relationship

\section{INTRODUCTION}

Launched on November 2009 by Brian Acton and Jan Koum, WhatsApp succeeded to make its place in the top 20 leading applications in US by early 2011 (Prathap et al. 2014). It was built with an intention to replace SMS by providing some additional information to users such as the double tick in blue color option of WhatsApp let users know that the recipient has read their message (Church \& De Oliveira, 2013). The main intention was to introduce an easy-to-use messaging product rather than developing new ways to glean customer information for marketing purpose (Bouhnik and Deshen, 2014). The new approach hits the bull's eye. With the passage of time, Interesting features have been added to application. Some of its major features include sending text messages, audio notes, videos, location details, files and many more. The recent free of cost calling feature with a fantastic sound quality has enthralled the users, making it even more interesting.

Communication technology was considered luxury in 20th century but slowly and gradually it becomes a necessity not only in the developed nations but in emerging and developing nations as well (Han, 2012; Yaovi et al, 2016; Hartje \& Hubler, 2015). Mobile phones were initially considered as only a source of communication and owned by only elite class in Pakistan. However, soon it has been observed that the gadget makes its place as an indispensible necessity of the new generation, irrespective of their economic class and social status (Ali et al, 2014; Aman, 2015; Ahmed, Qazi \& Pergi, 2011).

The use of WhatsApp is rapidly increasing in all the regions of the world including Pakistan. (Arif \& Kanwal, 2016; Hassan, 2017). Since February 2014 when Face book acquired WhatsApp, few 
changes have been made to the WhatsApp Messaging application in special reference to Pakistan. Having a long list of emojis for feelings' expressions, WhatsApp has now finally added Pakistani flag in its emoji list. (See figure 1 below) Moreover, there is now also support for Urdu and Bengali languages (see figure 2 below). WhatsApp is widely popular among the youth. 54\% Pakistani say that they use WhatsApp at least once a day. (Telenor Group, 2016). It allows users to send text, audio and video messages at no cost.

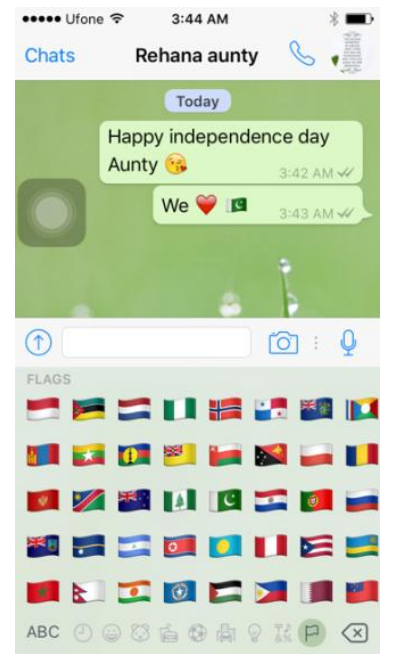

Figure1: WhatsApp Emojis

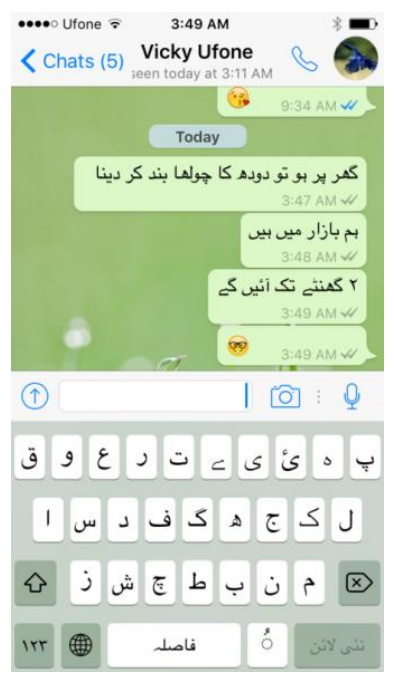

Figure2: WhatsApp Urdu Language Feature

However, in Pakistan, it has become much more than a cost effective chatting application. Recently, the concerned authorities start using WhatsApp to engage directly with the citizens of Pakistan. The Rangers of Pakistan have launched WhatsApp number 0316-2369996 for reporting crime scenes, unlawful activities and terror attacks. The Rangers appealed people to register complain on WhatsApp if anyone attempts to forcibly collect hides of sacrificial animals from them. They cautioned people that donating hides of animals to extremist and terrorist organization is tantamount to facilitating them. They may also attach video footage or photographs with their messages to add authenticity to complain.

However, the government and rangers are not on one page. The ministry of Interior issued a notification saying that WhatsApp topped the list of the most blacklisted applications by companies as the data is sent without being encrypted. He directed his employees to stop using WhatsApp which may post serious risks to organizations ("Interior ministry directs employees," 2017).

The concerned authorities of WhatsApp secure messages with end to end encryption. It ensures that your personal data is secured with a lock and it will not fall into wrong hands. The end to end encryption is enabled automatically in the latest versions of application. 
Tapping into the popularity of WhatsApp application, the editors of Pakistan have taken a new initiative to facilitate communication between editors about the missing journalists by creating a WhatsApp group entitled 'Editors for safety'. Recently Afzal Mughal, a Pakistani Journalist from Quetta was abducted from his home. Immediately a message was sent to WhatsApp group informing about the kidnapping incident. In less than five minutes 21 national and few international channels were running the story ("Pakistani Editors use WhatsApp group," 2016).

Another WhatsApp group was created by the concerned authorities of Special Education department with an intention to keep a check on the punctuality of the officials. The group is comprised of many seniors including Principals of Special Education Schools and linked directly with the office of Secretary Special Education. Regional directors and Principals of Special Education have been directed to share the attendance by 9:30 every morning. It had a positive effect on the attendance of the officials ("WhatsApp group created to check punctuality,"2016).

It wouldn't be an overstatement to say that WhatsApp has successfully managed to become an application which is being used worldwide to tackle many social political and economic challenges. However, we, as citizens of Pakistan are fast moving backward rather than forward in the evolutionary ladder of technology, science and innovations.

As cost effective application, Pakistan can make good use of WhatsApp in different organizations through different training sessions with proper planning. This study will create awareness in academic and business organization to make proper use of WhatsApp in order to deal with emerging economic challenges in Pakistan. Our business community is still far behind to comprehend the positive role that WhatsApp is playing in the developing countries. The study will not only highlight the ways through which WhatsApp is being used in academic and business communities but it will also foster the utilization WhatsApp in different government and private organizations in a sustainable manner. The coming five or 10 years will be critical time in which we can tackle the emerging challenges through WhatsApp. The goal can be achieved by providing knowledge about the proper use of WhatsApp through training, seminars and workshops. The study also provides a strong foundation for future research in order to understand how we can utilize it in better way.

This study revolves around the phenomenon that how many students and professionals are using WhatsApp and throws light on the role of WhatsApp in their daily life. This study will help in proposing a strategy for accommodating WhatsApp in academic and business communities.

\subsection{Significance of the study}

The study will be an important research work for exploring the possibilities of emergence of WhatsApp as the leading mobile messaging application in Pakistan. This study can be a learning exercise for understanding the increasing trend of WhatsApp among youth and professionals. In recent years, WhatsApp application has experienced an astronomical increase in Pakistan, making it an affordable communication tool for students and professionals. Yet no data is available about the content and composition of WhatsApp conversations. In developed countries, users have to pay $\$ 1$ as annual subscription charges after 1 year but recently the management of WhatsApp has decided not to charge even the annual fee of using its service from the developing states including Pakistan. This step opens the door wide for researchers in Pakistan. The increasing trend of WhatsApp messenger as an innovative communication device in the metropolitan city Karachi is a matter of newer subject of interest that needs evaluation and research based understanding.

The study will be beneficial from economic, social and political point of view as well as this study can play a vital role in the task of nation building, governance and in improving the quality of life of a lay man. In terms of novelty, to our knowledge, this is the first study to determine the frequency and composition of WhatsApp messages in Pakistan. Furthermore, WhatsApp bring down everyone under one platform where people can discuss their personal and professional stories in words, pictures and videos. It is also much cheaper than SMS and provides much more options than SMS. The findings can serve as a benchmark for surpassing SMS in terms of both cost and features.

\subsection{Research Objectives}

The objectives of this research are given below 
- To determine the frequency and composition of WhatsApp users in Karachi city.

- To determine the frequency of messages shared in each day by professionals and students in Karachi.

- To determine the frequency of media files shared by students and professionals in Karachi

- To find out the number of messages shared in day and night timings

- To discover the need and utilization of WhatsApp application by students and professionals of Karachi city.

- To analyze the difference of students and professionals conversations on WhatsApp application.

- To analyze the content of WhatsApp conversations.

\subsection{Literature Review}

With the advancement of digital technology and the emergence of mobile phones in Pakistan, the communication scenario has completely changed (Ali, Rizvi \& Sherdil, 2014). The increasing trend of smart phones and social networking applications in Pakistan has made communication faster and easier than at any time in history.

Now, people may not have enough money to eat, enough place to sleep and enough dress to wear but have mobile phone in their pockets to interact with their family members, friends and customers. With the changing scenario, use of quantitative and qualitative research techniques has also increased with the passage of time. Procedures were devised for the measurement of nature and effect of communication devises on human behavior. During the same period, smart phones and instant messaging application like WhatsApp, Viber and Skype took over the world of communication in Pakistan.

\section{Effects of Using Mobile Phones on ACAdemic Performance of Students}

Another study was done at the Islamia University of Bahawalpur, Pakistan to determine the effects of mobile phones on the academic performance of students. Data was gathered using a likert scale from a sample of 390 students. The findings showed that the mobile phones were beneficial for students to some extent. They could easily be in touch with each other through mobile phones and share information with class mates and teachers. Furthermore, Mobile phones made it easy for them to consult dictionaries and thesaurus for academic purpose. However, the findings of the study also showed that the use of mobile phone was wasting the precious time and money of students and diverting their attention. (Javaid, Ashraf \& Ahmed, 2011)

\subsection{Effects of Texting on Writing Skills and Language}

A comparative study was done to find out the percentage of English, Roman English and Urdu language by 50 male and female students of Lahore city. The findings revealed that the ratio of female is greater than male in using one single language as compared to mixed. (Ali \& Aslam, 2012) However, many loop holes were noticed during the analysis of this research which suggested that the results might not be considered authentic. So another research was analyzed in order to know the variation of language in SMS. Data of three months was gathered from 100 graduate students, both male and female. The findings of this study are significant in demonstrating that the habit of texting in different languages is affecting the spelling grammar and syntax of their second language (English) (Mahmood et al, 2015)

\subsection{Comparative Study on Messaging Application (Whatsapp) and SMS}

A survey was done by the company of Telenor to draw a comparison between SMS, voice calls and messaging application in seven countries including Pakistan, Malaysia, Thailand, Serbia, Hungary, Sweden and Norway in Dec 2015. Data was gathered from a sample of 5600 people, aged between 16-35. According to that survey, $74 \%$ Pakistani use their basic phone to make a traditional call several times per day, confirming the importance of traditional basic calls in this era of digital networking. $30 \%$ Pakistanis use the feature of video calling several times on daily basis. $49 \%$ Pakistanis use 
messaging application several times on daily basis. This is the lowest percentage among all surveyed country where the messaging apps users are more than half. 66\% Pakistanis use traditional sms to communicate, confirming the fact that the youth of Pakistan prefer traditional sms and voice calls over messaging application. 54\% Pakistanis agreed that they use WhatsApp at least once a day, beating face book messanger at 51 percent. It's interesting to note that the findings shows that the use of sharing location, map services and games is relatively low in Pakistan as compared to other online activities including picture and video sharing. (Telenor Group, 2016)

\section{EFFECT OF SOCIAL NETWORKING AND MESSAGING APPLICATIONS (INTERNATIONAL)}

According to the UK Communications Market Report (CMR) report which was published on 4rth August 2016, instant messaging has become one of the most popular form of communication. The proportion of people using instant messaging service is risen from $28 \%$ to 43 percent in 2016. Text messaging and emailing decline is noticed for the first time in UK. $82 \%$ respondents agreed that smart phone applications like WhatsApp and snap chat helps them to communicate with their loved ones and makes their life happy and easier than before. Therefore, substantial growth is noticed in number of people who are using instant messaging applications. According to the findings of the research, face book messenger has the largest number of users (22.5 million) and WhatsApp has the second highest number of users (16.7 million). It's mostly being used by people aged between 18 -34.

\subsection{Effect Studies of Social Phone Application on Business}

An experimental study was done at International Islamic University of Malaysia in order to find out about the relationship of smart phone applications and online business. Online questionnaire, likert scale and interviews were conducted from two major private and government companies to study their selling behavior in using smart phones. The respondents were asked about their experience and satisfaction level of shopping via smart phone. Pearson correlation coefficient statistical measurements were used to determine the usage of smart phone applications (specially WhatsApp and face book) for online business. The findings showed that the smart phone applications are helping business man to grow their business and they are using it for innovative advertisements of their products. (Ibrahim, 2014)

\subsection{Effect Studies of Instant Messaging on Interpersonal Relationship}

In order to evaluate possible effects of instant messaging on interpersonal relationship, a qualitative research was done at Chinese university of Hong Kong. In this regard, structured interview was conducted with 10 informants who were from diverse backgrounds and age groups. Many benefits and negative effects of instant messaging were mentioned by the informants. Some of the major benefits highlighted by informants were ease of use, potency, mobility and affordability. Furthermore, the findings showed that instant messaging is useful for interacting with close relationships only if managed properly. As it may increase misunderstandings, suspicion, arguments and deception between people which is a potential harm to relationship. The informants reported that they feel a kind of anxiety when they do not get back reply from other person. (Lin, 2012)

\subsection{Effect Studies of Social Phone Application on Vocabulary and Language}

A study was done at Allama Mohammad Ibn Saud Islamic University in Saudi Arabia. The study was related to prospective benefits of WhatsApp in improving language skills. It was a quantitative and quasi-experimental study. Data was gathered from 30 under graduate students who had to express their views on different general topics on a WhatsApp group. The students participated well in the discussions and the findings indicated a significance difference between the pre test and the post test. An improvement in vocabulary and word choice of the students was noticed. (Alsaleem, 2013)

\subsection{Effect Studies of Social Phone Application on Academic Performance}

A quantitative study was done in Ghana to find out the impact of social media networks on performance of high school students. A survey was done from the students of four high school students and then an interview was carried out from the heads of these high schools. The findings showed that effects can be both positive and negative depending on their usage. The positive effects include sharing information and improving writing and reading skills. The misuse of these social 
media networking sites may negatively affect the performance and academic life of students. (mingle, adams, 2015)

\subsection{Effect Studies of Whatsapp on Health Care Education}

A qualitative and descriptive study was done with an objective to analyze the experiences of 21 undergraduate nurses on WhatsApp who were enrolled at a school of nursing in South African University. A WhatsApp group was formed and a discussion was initiated about health care education. Later their experiences were collected through email. The results indicated the positive benefits of using WhatsApp for clinical practice and collaborative learning. The platform provided much material and resources for the preparation of tests which students can share and discuss with each other. The study also highlighted the fact that excessive use of WhatsApp may lead to low battery as well which is annoying at times. (Willemse, 2015)

\subsection{Effect Studies of Whatsapp on Grammar}

An experimental study was done in private university of Saudi Arabia out the impact of WhatsApp on the writing skills of college students. In this regard, 30 students were selected from English department. In order to improve their writing skills, half students were taught through academic books whereas half of them were taught through WhatsApp. 3 questions were included in pre test and post test which were related punctuation, sentence structure and writing essay. The findings show that the experimental group performed better than the control group. (Fattah, 2015)

\subsection{Effect Studies of Whatsapp on Distant Learning}

A descriptive focus study was done in University of Cape town by Navarai Tuniera in which Salmon's (2000) 5-stage model and interaction analysis model were used for using WhatsApp groups as a way to reduce transactional distance. It was a case study of six pre-service teachers and the unit of analysis was distance students. Researcher was also part of WhatsApp group. Afterwards, an interview was taken with three of the students to determine their social knowledge and the role of WhatsApp. In the end focus group discussion was initiated. The findings confirm the notion that the WhatsApp group activity has positive influence on students and it helped them to construct their social knowledge. It also helped them to connect with each other informally. (Tunjera, 2014)

\subsection{Effect Studies of Whatsapp on Psychological Behavior}

A study was done in Jalandhar district Punjab to evaluate the relationship between psychological behavioral factors on WhatsApp addiction among youth of India. Survey method was chosen to collect data from 150 respondents both males and females. The findings showed that WhatsApp users feel tensed, lonely and stressed after not getting their expected reply on WhatsApp and there is a strong relation between WhatsApp and moody behavior.

Different Quantitative and Qualitative Methods like semi structured interviews, half structure interview, baseline and large scale surveys, , quasi-experimental study were devised for the measurement of aspects of WhatsApp users so the result obtained by one method could be compared with the finding of others. The objectives of the researchers were to analyze the linguistic features of WhatsApp communication, its advantages and disadvantages, its effects on educational activities, relations intimacy and lifestyle and more. Their work provides a deeper understanding of how and why Smartphone users have adopted and appropriated WhatsApp in the daily lives and explain which factors influence the acceptance, usage and growing popularity of such MIM applications, in particular compared to SMS.

\section{Methodology}

The present research study is a quantitative and qualitative analysis of WhatsApp conversations. "Mixed methods research is formally defined as the class of research where the researcher mixes or combines quantitative and qualitative research techniques into a single study" (Onswuegbuzie, A. J., \& Johnson, R. B., 2004). Mixed methods research adds more detail and description which increases validity of findings. (Van Zoonan, 1994). In this regard, a combination of quantitative and qualitative method is used in this study to evaluate the findings in detailed manner. 


\subsection{Variables}

- Independent Variable: WhatsApp messenger use

\subsection{Dependent Variables}

- Language (How WhatsApp is affecting our language)

- Everyday Activities (How WhatsApp is affecting our everyday activities for example. business, academic activities etc)

- Interpersonal Relationship (How WhatsApp is affecting our relationships)

\subsection{Unit of Analysis}

- Each and every message of the conversation was considered unit in this analysis.

50 conversations were chosen in a way that they were representative of the city as a whole. In order to obtain a representative, and statistically valid sample of the whole, an attempt has been made to divide the students in three main classes; Upper class, Middle Class and Lower Class (A, B and C respectively). Then, the areas of Karachi were categorized accordingly; the areas of Defence, Clifton, PECHS and KDA were included in A Class. The areas of Federal B Area and Gulshan Iqbal were included in B Class and areas of Lyari, Orangi, Korangi were included in C class respectively. The key variables in this determination were age, gender, education, income and occupation. WhatsApp conversations were taken from 25 students and 25 professionals.

\begin{tabular}{|l|l|l|l|}
\hline \multicolumn{1}{|c|}{ University Name } & Class & \multicolumn{1}{c|}{ Category } & \multicolumn{1}{c|}{ Area } \\
\hline SZABIST & A & Business & Clifton \\
\hline Iqra University & A & Business & Defence \\
\hline Indus Valley School of Art and Architecture & A & Arts & Clifton \\
\hline University of Karachi & B & General & Main University Road \\
\hline NED University of Engineering \& Technology & B & Engineering & Main University Road \\
\hline Baqai Medical University & B & Medical & Super highway \\
\hline Preston University (Korangi Campus) & C & General & Korangi \\
\hline Jinnah University for Women & C & General & North Nazimabad \\
\hline The Nazeer Hussain University & C & General & Karimabad \\
\hline
\end{tabular}

The professionals were taken from different occupational backgrounds including (Doctors, Engineers, Architectures, Shopkeepers, Business men, Bankers, Dress Designers, Chefs, Teachers, Electricians, Journalists, Lawyers, Celebrities, and Politicians)

Due to the law and order situation of Pakistan, people were not so comfortable to share their conversations with the researcher. So, informed consent form was given to them in which the purpose of research was clearly mentioned. They were informed that the information gathered during this study will remain confidential. There will not be any identifying name or phone number on screenshots of conversations. Their name or any other identifying will never be revealed in any publication of the results of this study. They were also informed about the importance of this study that the knowledge obtained from this study will be beneficial in guiding students and professionals about the proper use of WhatsApp application. Furthermore, they were free to participate. Participation was voluntary.

Quantitative analysis is done to find out the frequency of WhatsApp users in Karachi and a qualitative analysis was done to analyze at both linguistic features and usage behavior of WhatsApp users in Karachi.

The quantitative data was analyzed through Python language which is an increasingly popular tool for data analysis. A total number of 50 conversations were analyzed in order to see the frequency of words, messages and media files. Some conversations were of months while some were of few days so a criteria was chosen in beginning according to which conversation of 15 days were analyzed.

For qualitative analysis of data, it was categorized in terms of language, activities and tone of conversation. Unit of analysis was a single message. In order to cover all type of conversations, data was further categorized in private and group conversations according to the following criteria. 


\subsection{Whatsapp Groups}

\begin{tabular}{|l|l|}
\hline Task Oriented & $\begin{array}{l}\text { This category includes WhatsApp groups which are formed for completion of any task } \\
\text { for a limited duration of time. }\end{array}$ \\
\hline Assigned groups & $\begin{array}{l}\text { This category includes WhatsApp groups where members are being asked to be a } \\
\text { member of WhatsApp group. }\end{array}$ \\
\hline $\begin{array}{l}\text { Emergent } \\
\text { Groups }\end{array}$ & $\begin{array}{l}\text { This category includes WhatsApp groups where different people belonging to } \\
\text { different cast, culture or background decide to make a WhatsApp group in order to be } \\
\text { keep in touch with each other. }\end{array}$ \\
\hline Paid Groups & $\begin{array}{l}\text { This category includes WhatsApp groups where members have to pay specific amount } \\
\text { to be a part of that group. }\end{array}$ \\
\hline $\begin{array}{l}\text { Relationship } \\
\text { Oriented }\end{array}$ & $\begin{array}{l}\text { This category includes WhatsApp groups where people who already know each other } \\
\text { form a group to share some content or information with each other }\end{array}$ \\
\hline $\begin{array}{l}\text { Purpose } \\
\text { Oriented }\end{array}$ & $\begin{array}{l}\text { This category includes WhatsApp groups in which People whose goals are similar } \\
\text { form a group to share their experiences with each others. }\end{array}$ \\
\hline Global groups & $\begin{array}{l}\text { This category includes WhatsApp groups in which different types of people having } \\
\text { common interests participate from different countries around the globe }\end{array}$ \\
\hline Family Groups & This category includes conversations of student and professional's families. \\
\hline
\end{tabular}

\subsection{Private Chats}

\begin{tabular}{|l|l|}
\hline Students (boys) & This category includes private chats of two male students \\
\hline Students (girls) & This category includes private chats of two female students \\
\hline Students (Mix gender) & This category includes private chats of two female and male students \\
\hline Professionals (Men) & This category includes private chats of two male professionals. \\
\hline Professionals (Women) & This category includes private chats of two female professionals \\
\hline Professionals (Male \& Female) & This category includes private chats of two male and female professionals \\
\hline Family & $\begin{array}{l}\text { This category includes private chat between family members of students } \\
\text { and professionals }\end{array}$ \\
\hline
\end{tabular}

\section{DISCUSSION OF RESULTS}

The study has revealed that WhatsApp application has great potential of growth in developing countries like Pakistan. More than 1 billion people around globe are using WhatsApp application to keep in touch with their family members, colleagues and friends. WhatsApp is connecting almost 180 countries. The summary of the major findings related frequency of words, messages and media files is given below

- A total number of 33 messages were sent in a single day by each user of WhatsApp living in Karachi

- A total number of 430 words were shared in a single day by each user of WhatsApp living in Karachi

- A total number of 3 media files were shared in a single day by each user of WhatsApp living in Karachi.

- A total number of 66,327 messages were sent by 2,023 WhatsApp users in 30 days

- A total number of 869,404 words were shared by 2,023 WhatsApp users in 30 days

- A total number 6163 media files were shared by 2,023 WhatsApp users in 30 days.

- 23620 (35.61\%) messages were sent at A.M and 42707 (64.39\% )messages were sent at P.M

We may conclude that Pakistan is not lagging behind in the race of technology and innovation. The findings of this study show that $97 \%$ student and $91 \%$ professionals living in Karachi use WhatsApp to stay in touch with people. They are devoting countless hours to WhatsApp and making it a cultural, political and social phenomenon. people living in Karachi prefer to send messages in day timings.

\subsection{Language and Tone of Whatsapp Conversations}

The tone of $21(42 \%)$ conversations was informal. The tone of $13(26 \%)$ conversations was semi formal and the tone of $16(32 \%)$ conversations was formal so we may conclude that people usually talk in informal manner on WhatsApp. The first most used language was roman English which was 
used in 25(50\%) conversations where as English was used as a first most used language in 14 (28\%) conversations and urdu was used as a first most language in 11(22\%) conversations. 22 (44\%) Conversations were in single language where as $28(56 \%)$ conversation were in two language. Roman English was used as second most used language in $10(20 \%)$ conversations where as Urdu and English were used as a second most language in 9 (18\%) conversations. All the three languages (Urdu, Roman English, and English) were used in 11 conversations. Roman English was used as a third most used language in $5(10 \%)$ conversations where as English was used a third most language in $4(8 \%)$ conversations and Urdu was used as a third most language in $2(4 \%)$ conversations.

We may conclude that the tone of their conversation is mostly informal. Students prefer to send messages in roman English while professionals prefer using English or Urdu in their conversations.

\subsection{Comparison of WhatsApp conversations}

A notable difference was observed while analyzing conversations of family members, professionals and students. It's categorized according to their percentage in table below

\begin{tabular}{|l|l|l|l|l|}
\hline \multicolumn{1}{|c|}{ In 30 days conversation } & \multicolumn{1}{c|}{ Family Members } & \multicolumn{1}{c|}{ professionals } & \multicolumn{1}{c|}{ Students } & \multicolumn{1}{c|}{ Total } \\
\hline No. of Messages & $2882(4.35 \%)$ & $24750(37.31 \%)$ & $38695(58.34 \%)$ & $66327(100 \%)$ \\
\hline No. of words & $113570(13.06 \%)$ & $345302(39.72 \%)$ & $410532(47.22 \%)$ & $869404(100 \%)$ \\
\hline No. of media files & $1338(21.71 \%)$ & $3094(50.2 \%)$ & $1731(28.09 \%)$ & $6163(100 \%)$ \\
\hline No. of messages shared at AM & $688(2.91 \%)$ & $7450(31.54 \%)$ & $15482(65.5 \%)$ & $23620(100 \%)$ \\
\hline No. of messages shared at PM & $2194(5.14 \%)$ & $17300(40.51 \%)$ & $23213(54.35 \%)$ & $42707(100 \%)$ \\
\hline No. of people & $98(4.84 \%)$ & $1531(75.68 \%)$ & $394(19.48 \%)$ & $2023(100 \%)$ \\
\hline
\end{tabular}

- Each student has shared 98 messages in 30 days. Each professional has shared 16.6 messages in 30 days. Each family member has shared 29.40 messages in 30 days so we can conclude that students are sharing more messages than professionals and family members

- Each student has shared 4.39 media files in 30 days. Each professional has shared 2.02 media files in 30 days. Each family member has shared 13.65 media files in 30 days so we may conclude that family members do like to share media files like videos/images with each other more than professionals and students. We may also notice that the frequency of sharing media files is higher in students as compared to professionals so we may conclude that students share more media files than professionals.

- Each student has sent 1041.95 words in 30 days. Each professional has sent 225.54 words in 30 days. Each family member has sent 1158 words in 30 days so we may say that family members are using more words in conversations as compared to students and professionals.

- A single message of a family member is composed of 39.40 words. A single message of a professional is composed of 13.95 words. A single message of a student is composed of 10.60 words. Forward messages are generally composed of so many sentences and words and everyday conversation is composed of few sentences and words so we may conclude that family members send forward messages to each other more than professionals and students. We may also notice that messages of students are composed of fewer words as compared to professionals so we may conclude that students share less forward messages as compared to professionals and family members.

- Students share $40.01 \%$ messages in late night (AM) and 58.98\% messages in day timings (PM). Professionals share $30.10 \%$ messages in late night (AM) and $69.89 \%$ messages in day timings (PM). Family members share $23.87 \%$ messages in late night (AM) and $76.12 \%$ messages in day timings (PM). So we may conclude that students share more late night messages as compared to professionals and family members.

\subsection{Linguistic Menfestation of WhatsApp conversations}

WhatsApp has a major impact on the development of language across the globe. It was discovered that students and professionals have developed their own generational slang on WhatsApp. A lot of abbreviations, clipping, code mixing, homophones, reduplication, misspelled words were observed during analysis. Some of them are given below 
Content Analysis of Whatsapp Conversations: An Analytical Study to Evaluate the Effectiveness of Whatsapp Application in Karachi

\begin{tabular}{|l|l|l|l|}
\hline $\begin{array}{l}\text { Linguistic } \\
\text { Menifestation }\end{array}$ & Definition & $\begin{array}{l}\text { Examples from WhatsApp } \\
\text { Conversations }\end{array}$ & Original words \\
\hline Initialism & $\begin{array}{l}\text { Abbreviation consisting of } \\
\text { initial words }\end{array}$ & Asap, tc, lol & $\begin{array}{l}\text { As soon as possible, take } \\
\text { care, lots of laughter }\end{array}$ \\
\hline Clipping & $\begin{array}{l}\text { A small piece that has been } \\
\text { clipped off or out something }\end{array}$ & Bro, exam, uni, congrats & $\begin{array}{l}\text { Brother, examination, } \\
\text { university, congratulations }\end{array}$ \\
\hline Code mixing & $\begin{array}{l}\text { Mixing of two or more } \\
\text { languages in sentence or phrase }\end{array}$ & $\begin{array}{l}\text { Inka solution bhej do, } \\
\text { game khel taha tha }\end{array}$ & $\begin{array}{l}\text { Send solution, I was } \\
\text { playing game }\end{array}$ \\
\hline $\begin{array}{l}\text { Single } \\
\text { letter/number } \\
\text { homophone }\end{array}$ & $\begin{array}{l}\text { A single letter or number } \\
\text { that is pronounced and sound } \\
\text { same as the original word }\end{array}$ & y, v, m,k & Why, you, we, amay \\
\hline $\begin{array}{l}\text { Alphanumeric } \\
\text { homophone }\end{array}$ & $\begin{array}{l}\text { A word consisting of both } \\
\text { letters and number }\end{array}$ & w8, b4,4get, msu2 & $\begin{array}{l}\text { Wait, before, forget, miss } \\
\text { you too }\end{array}$ \\
\hline $\begin{array}{l}\text { Reduplication of } \\
\text { word/punctuation }\end{array}$ & $\begin{array}{l}\text { Word or punctuation sign } \\
\text { which is formed by repeating } \\
\text { last/ first word of a sentence }\end{array}$ & $\begin{array}{l}\text { ??????????, } \\
\text { hmmm, yessss }\end{array}$ & ?hhh, oh, hm, yes, \\
\hline Misspelled words & words with incorrect spelling & Purrfect, lub yew, Thanx & Perfect, love you, Thanks \\
\hline
\end{tabular}

\subsection{Academic Activities on WhatsApp}

It was observed that students not only use WhatsApp for daily communication but for discussion related academic stuff as well. They ask each other to share pictures of notes and discuss about attendance as well. They discuss about the details of assignments with each other. They often ask each other to share relevant links on WhatsApp about assignment. They often plan on WhatsApp to arrange a group study in last hours before exam. They often discuss about paper pattern on WhatsApp and ask other student to learn half questions who will sit beside them. They share past papers on WhatsApp. They ask each other to mark their attendance when they are absent by responding teacher in his voice. There were also some groups in which teacher is guiding students on WhatsApp. Thus we may say that WhatsApp has enhanced effective flow of information among students. There are several studies which are consistent with the findings. The insertion of technologies like WhatsApp in academic institute is significant as students usually find traditional class teaching too static and boring (Ballesteros, D., Jiménez, J., López J., \& Menéndez, M, 2013; Blehch, A. 2014)

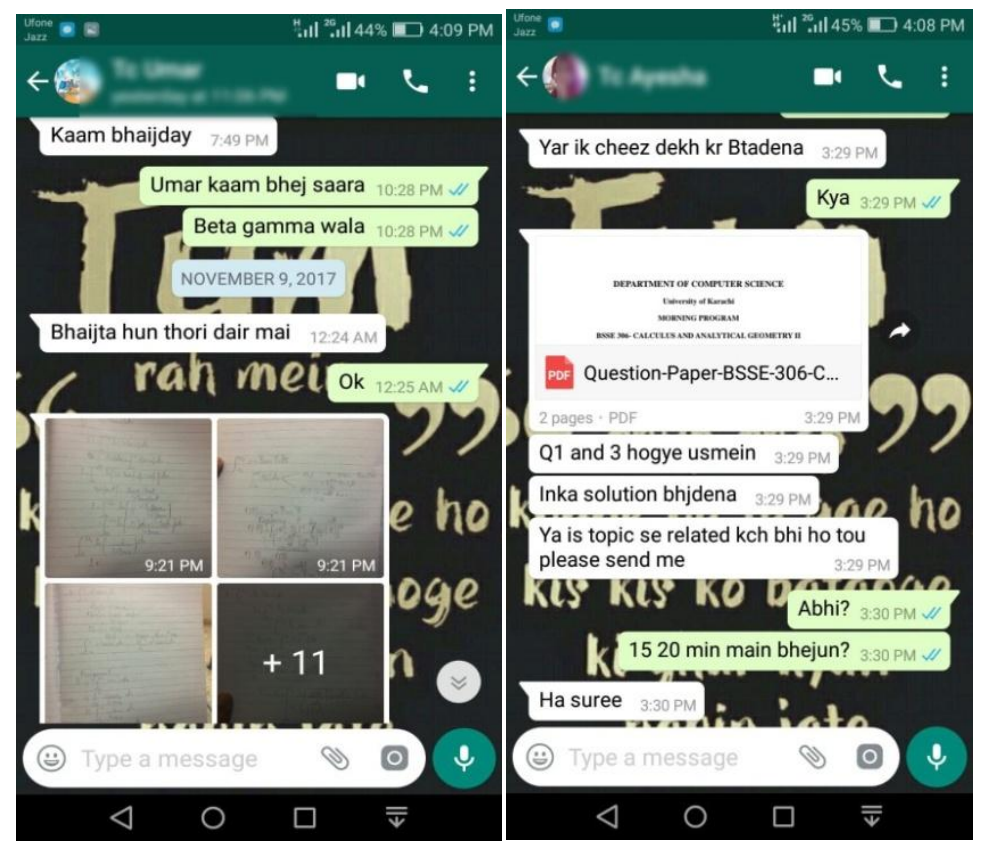

\subsection{Business Activities on WhatsApp}

WhatsApp can be used to affordably communicate with internal and external public in different ways. It was observed that businessman and professionals use WhatsApp to share management decisions with sub ordinates, to plan meetings, to update about different promotional schemes. They use location feature of WhatsApp to inform their customers about physical location of their shop. They advertise their products on WhatsApp and also share discount offers on WhatsApp. Thus we can say 
that WhatsApp enables professionals to stay in touch with each other and to promote their business without paying much.

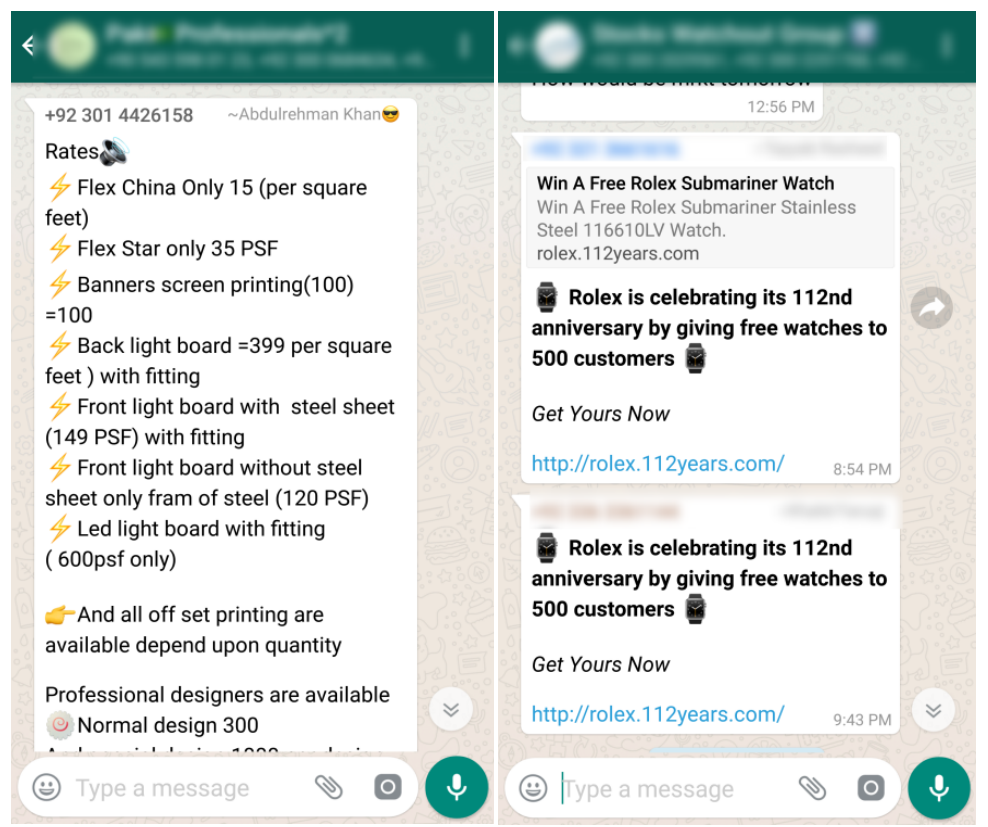

\subsection{Relationships on WhatsApp}

The findings show that WhatsApp help students and professionals in building relationship. WhatsApp provides a venue where both students and professionals can interact with their loved ones, customers, friends, family members, mentors without any time restriction. Hence we can say that WhatsApp is a powerful tool that enables people to build and break relations. Apart from text and media files, people communicate through emoticons. When we write something, emojis act as non verbal cues that provide so much information which is not possible to deliver through words only. These pictorial reflections of sentiments are playing a vital role in our everyday conversation.

\subsection{Entertainment activities on WhatsApp}

It was observed that there are several groups which connect people belonging to different cultures, countries and interest. There are different types of groups which include funny videos, pranks, jokes, poetry groups. There are proper rules and regulations for these groups and group admin often initiates some sort of activities in group to engage people.

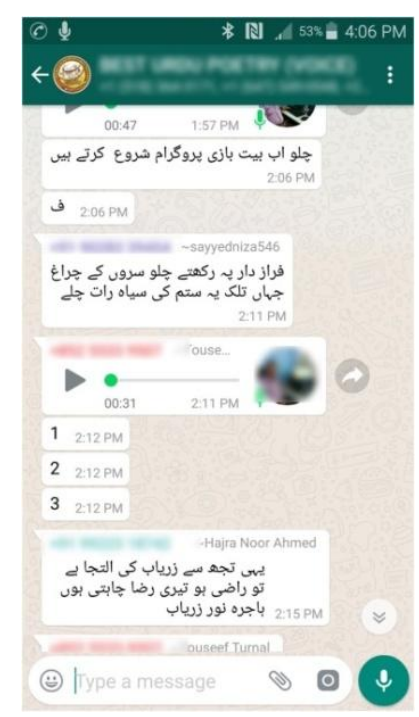

\section{CONCLUSION}

The purpose of this study was to investigate how students and professionals interact with each other and how they use WhatsApp to fulfill their academic, business and personal goals. It is concluded that 
WhatsApp plays a vital role in lives of students and professionals. A single person is sharing minimum 33 messages comprised of 430 words and almost three media files on WhatsApp in a single day. They prefer to use WhatsApp in day timings. Both students and professionals are using WhatsApp in numerous ways like exchanging casual and important information, discussing issues related studies and keeping in touch with relatives, friends, colleagues and people living in abroad. They also use it to advertise, sell \& purchase products. It's also being used as a tool for sharing emoticons and sentiments. It was also discovered that students are using WhatsApp more frequently than professionals.

Thus we can say that WhatsApp has become an important part of daily lives of students and professionals. It enables people to cooperate and work as a team. They utilize different features of WhatsApp which help them in their studies, business and personal life. It's much quicker and affordable way to interact with people which enhance the effective flow of communication.

\section{REFERENCES}

[1] Ahmed, I., Fiaz, T., Aijaz, K. (2011). "Mobile phone to youngsters: Necessity or addiction", African Journal of Business Management Vol.5 (32), pp. 12512-12519

[2] Ali, S., Rizvi, S. A. A.,\& Qureshi. M.S. (2014). Cell phone mania and Pakistani youth: Exploring the cell phone usage patterns among teenagers of South Punjab. FWU Journal of Social Sciences, 8(2), 43-48.

[3] Ali, I., \& Aslam, T. M. (2012). Frequency of learned words of English as a marker of gender identity in SMS language in Pakistan. Journal of Elementary Education, 22 (2), 45-55.

[4] Aman T, Shah N, Hussain A, Khan A, Asif S, Qazi A. Effects of mobile phone use on the social and academic performance of students of a public sector medical college in khyber pakhtunkhwa pakistan. Khyber J Med Sci. 2015;8(1):99-103.

[5] Arif, M., Kanwal,S. (2016). "Adoption of Social Media Technologies and their Impact on Students' Academic Performance: The only Way for Future Survival of Distance Education Students in Pakistan". Pakistan Journal of Information Management \& Libraries. Vol. 18 No.1, 25-36

[6] Bouhnik, D., \& Deshen, M.(2014).WhatsApp goes to school: Mobile instant messaging between teachers and students. Journal of Information Technology Education: Research, 13, 217-231

[7] Ballesteros, D., Jiménez, J., López J., \& Menéndez, M. (2013). Impact of new technologies and social networks on a secondary education theatre project. NEM Summit Proceedings, 111-116

[8] Blehch, A. (2014). The impact of WhatsApp mobile social learning on the achievement and attitudes of female students compared with face to face learning in the classroom. European Scientific Journal.10. (22).

[9] Church, K., \& de Oliveira, R. (2013). What's up with WhatsApp? Comparing mobile instant messaging be-haviors with traditional SMS. Proceedings of the 15th International Conference on Human-computer Interaction with Mobile Devices and Services

[10] Han.C (2012). South African Perspectives on Mobile Phones: Challenging the Optimistic Narrative of Mobiles for Development. International Journal of Communication 6 (2012), 2057-2081

[11] Hartje \& Hubler, 2015 Are smart phone smart for economic development, Hannover Economic Papers (HEP) No. 555 ISSN 0949-9962

[12] Hassan, B., \& Unwin, T. (2017). Mobile identity construction by male and female students in Pakistan: On, in, and through the phone. Information Technologies \& International Development, 13, 87-102.

[13] Ibrahim, J.; Ros, R.C.; Sulaiman, N.F.; Nordin, R.C. \& Yuan, L.Z. (2014). Positive impact of Smartphone application: WhatsApp \& Facebook for online business. International Journal of Scientific and Research Publications, 4 (2), 1-4.

[14] Interior ministry directs employees to refrain from using WhatsApp (2017, November 3), Pakistan today. Retrieved from https://www.pakistantoday.com.pk/2017/11/03/interior-ministry-directs-employees-torefrain-from-using-WhatsApp/

[15] Lin S. (2012). Instant messaging on interpersonal relationship: How it brings intimacy and negative feelings? Masters Thesis, School of Journalism and Communication. The Chinese University of Hong Kong, Hong Kong

[16] Mingle, Jeffrey and Adams, Musah, (2015). "Social Media Network Participation and Academic Performance In Senior High Schools in Ghana", Library Philosophy and Practice (e-journal). 1286.1-52

[17] Mahmood, Q., Iqbal, S., Zaidi, S. S. B., \& Ahmad, M. (2015). Exploring SMS (Short Message Service) as Language Variations: A Reflection on English Language Users in Pakistan. Journal of Policy Research, $1(1), 21-30$. 
[18] Ofcom, (2014). Communications Market Report 2016

[19] Onswuegbuzie, A. J., \& Johnson, R. B. (2004, April). Validity issues in mixed methods research. Paper presented at the annual meeting of the American Educational Research Association, San Diego, CA.

[20] Prathap J., Jubilson A., Dhanavanthini P., Rajkumar, S., Shibu J., \&Dani, V. (2014). Facebook WhatsApp merger - a revolution in the social networks. International Journal of Electrical \& Computer Sciences. 14 (04). 17-24

[21] Pakistani Editors use Whatsapp group to keep journalists safe (2016, February 10), Pakistan press foundation. Retrieved from https://www.pakistanpressfoundation.org/pakistani-editors-use-WhatsAppgroup-to-keep-journalists-safe/

[22] Singh, Navjit., Chopra, Nidhi., Kaur, Jaspreet. (2014). A Study to Analyze Relationship between Psychological Behavioural Factors on WhatsApp Addiction among Youth in Jalandhar Distric in Punjab. European Journal of Bussines and Management. Vol.6, no.37, 269-273

[23] Telenor Group. (2016). Youth hooked on mobile messaging but preference varies, says Telenor research. [online] Available at: https://www.telenor.com/media/press-release/youth-hooked-on-mobile-messagingbut-preference-varies-says-telenor-research/ [Accessed 2 Feb. 2017].

[24] WhatsApp group created to check punctuality of officials (2016, December 6), Samaa. Retrieved from https://www.samaa.tv/technology/2016/12/WhatsApp-group-created-to-check-punctuality-of-officials/

[25] Van Zoonan, L. (1994). Feminist Media Studies. London and New York: Sage.

[26] Willemse, J.J., 2015, 'Undergraduate nurses reflections on WhatsApp use in improving primary health care education', Curationis38(2), Art. \#1512, 7 pages.

[27] Yaovi M. G. Hounmanou, Murielle S. S. Agonsanou, Victorien Dougnon, et al., "The Necessity of Mobile Phone Technologies for Public Health Surveillance in Benin," Advances in Public Health, vol. 2016, Article ID 5692480, 7 pages, 2016. doi:10.1155/2016/5692480

Citation: Sana Shahid. "Content Analysis of Whatsapp Conversations: An Analytical Study to Evaluate the Effectiveness of Whatsapp Application in Karachi". International Journal of Media, Journalism and Mass Communications (IJMJMC), vol 4, no. 1, 2018, pp. 14-26. doi:http://dx.doi.org/10. 20431/2455-0043.0401002

Copyright: (C) 2018 Authors. This is an open-access article distributed under the terms of the Creative Commons Attribution License, which permits unrestricted use, distribution, and reproduction in any medium, provided the original author and source are credited. 